Original Research Article

\title{
Comparative study of anti-inflammatory property of calcium channel blocker and aspirin in albino rats
}

\author{
Anjum Jabeen*
}

\begin{abstract}
Department of Clinical
Pharmacology, Jeevan Scientific

Technology Limited,

Hyderabad, Telangana, India
\end{abstract}

Received: 12 October 2018

Accepted: 01 November 2018

\section{*Correspondence to: \\ Dr. Anjum Jabeen, \\ Email: anjumtabrez123@ \\ gmail.com}

Copyright: (C) the author(s), publisher and licensee Medip Academy. This is an openaccess article distributed under the terms of the Creative Commons Attribution NonCommercial License, which permits unrestricted noncommercial use, distribution, and reproduction in any medium, provided the original work is properly cited.

\begin{abstract}
Background: Calcium channel blockers are being used in the treatment of hypertension, ischemic heart disease, cardiac arrhythmias etc. They act by blocking the slow calcium channels. Influx of calcium is an essential step in the release of histamine and 5HT from mast cells and in the synthesis and release of prostaglandins. They are the main mediators in the process of inflammation. The aim of the present study was to compare anti-inflammatory properties of calcium channel blockers and aspirin in albino rats.
\end{abstract}

Methods: Present study was prospective intervention study carried out to compare anti-inflammatory properties of calcium channel blockers and aspirin in albino rats. Total 30 albino rats were used, and they were divided into 5 groups of 6 each. First group of rats was control group where normal saline was used. Second group was standard group where aspirin was used. Remaining three groups were test groups and given nifedipine, amlodipine and diltiazem respectively. Effects were observed and compared between the groups.

Results: In carrageenan method, the anti-inflammatory response of Aspirin was significantly higher. Nifedipine response was <aspirin but >diltiazem. The response of amlodipine was not significantly $>$ that of control percent inhibition. In histamine method, the anti-inflammatory response of aspirin was significantly highest. Anti-inflammatory response of nifedipine was < aspirin but > diltiazem. Diltiazem response was < nifedipine but > amlodipine. In formaldehyde method, aspirin inhibition was highest at $96.2 \%$ followed by nifedipine $(90.7 \%)$, diltiazem $(75.9 \%)$ and amlodipine $(3.7 \%)$. In cotton wool pellet granuloma, the mean dry granuloma weight was least for aspirin and percent anti-inflammatory activity was significantly high.

Conclusions: Calcium channel blockers (nifedipine, diltiazem) have shown comparable anti-inflammatory property with that of aspirin. Further clinical studies are required for confirmation.

Keywords: Albino rats, Amlodipine, Diltiazem, Effects, Nifedipine

\section{INTRODUCTION}

Many of the human diseases are associated with inflammation, a protective response to various stimuli. But if the response is exaggerated the same process becomes harmful and calls for treatment. The inflammation process is so dynamic that it offers a number of parameters for the investigator seeking to inhibit the inflammation and the very availability of these parameters have led to a multiplicity of methods of testing for anti-inflammatory activity. ${ }^{1}$
The term anti-inflammatory used clinically refers to an agent which will lessen prevent one or more of the various recognized components of inflammatory reaction. The mechanism and causes of clinically important inflammatory conditions have been found to be very complex and intricate and vary with the disease. Hence the effectiveness of different drugs varies accordingly. Most of the currently available NSAIDs control inflammation by inhibiting synthesis of inflammatory mediators by acting on cycle oxygenase. Other class of the drug's mainly; steroidal anti-inflammatory drugs inhibit phospholipase A2 enzyme. $^{2}$ 
Interestingly several newer compounds such as heterocyclic aryl acetic acid derivates propionic acid derivates of inflammogens monoclonal antibodies and analgesics of inflammogens. Interestingly several other drugs like minocycline ascorbic acid and calcium salts (calcium dobesilase calcium hydroxide, calcium salts have been reported to possess anti-inflammatory property. Aspirin is an age-old drug widely used as an analgesic which alleviates pain without affecting consciousness. It was introduced by Dr. Hemich Dresser as an analgesic, but its anti-inflammatory action was demonstrated only after the demonstration of anti-inflammatory action of cortisone in 1948. Recent advances on various actions of aspirin on different symptoms warrants a relook into its exciting new possibilities like its role in reducing the risk of fatal and non-fatal heart attacks, stroke's, migraine, cataract colorectal carcinoma and in control of pre-eclampsia pregnancy. 3,4

Calcium channel blockers are being used in the treatment of hypertension, ischemic heart disease, cardiac arrhythmias etc. They act by blocking the slow calcium channels. Influx of calcium is an essential step in the release of histamine and 5HT from mast cells and in the synthesis and release of prostaglandins. They are the main mediators in the process of inflammation. ${ }^{5}$

While increased calcium may potentiate nociception or inflammatory events decreased calcium may reduce such events intra-dermal injection of calcium results with acute inflammation. ${ }^{6}$

Hence the present study was planned to compare antiinflammatory properties of calcium channel blockers and aspirin in albino rats.

\section{METHODS}

Present study was prospective intervention study carried out at Deccan Medical College, Hyderabad during to compare anti-inflammatory properties of calcium channel blockers and aspirin in albino rats. Total 30 albino rats were used, and they were divided into 5 groups of 6 each. First group of rats was control group where normal saline was used. Second group was standard group where aspirin was used. Remaining three groups were test groups and given nifedipine, amlodipine and diltiazem respectively. Effects were observed and compared between the groups. The anti-inflammatory activity was determined by producing inflammation in rats of either sex. The materials used was chemical and solutions like aspirin, calcium channel blockers, nifedipine, amlodipine, diltiazem, carrageenan, histamine, formaldehyde, double distilled water and animals male-female rats were used in this experiment.

Rats were weighing between 150-250gm. Animals were procured from central animal house of the Deccan Medical College, Hyderabad. They were housed in cages in standard laboratory conditions with natural light and dark cycle and at room temperature. Food and water were given ad libitum. The protocol was approved by the Institutional Animal Ethical Committee (IEC).

Equipment used were mercury plethysmograph, insulin syringes, bell jars and glass beakers, animal weighing balance, animal cages, cotton pellets, stop watch, oral feeding tubes, spirit, skin suturing set, dissection set, $5 \%$ aqueous solution of amlopicillin, disposable needles, and markers. The drugs were administrated by oral feeding tubes.

\section{Method of using the apparatus}

An ink mark is made on a fixed point on the angle of the ankle joint of the rat. Now the limb is introduced gently into the mercury vessel. The mark of the limb and mercury level marks of the vessel are made parallel to each other. Within a few seconds the excess mercury passes and settles in the conjoined capillary where the mercury level is read. At the time of taking the reading, the ink marks of the animal limb. The mercury level mark of the glass vessel and the actual mercury level in the vessel should be accurately in one line. At this stage the capillary level of the mercury shows the amount of mercury displaced by the paw of the animal and indicates the paw volume.

\section{Methods of inducing inflammation}

- Method 1: Acute Model of inflammation: carrageenan induced hind paw edema in rats or Histamine induced Hind paw edema in rats.

- Method 2: Sub-acute model of inflammation: granuloma pouch method by implanting cotton palettes.

- Method 3: Chronic model of inflammation: formaldehyde induced hind paw edema.

\section{Method 1 (A): carragenean induced hind paw edema in rats (Winter et al, 1962)}

The method used here in comprises the study of the acute inflammatory reaction induced by the carrageen injected into the sub-plantar surface of the right hind paw of rat according to the method of Winter et al. ${ }^{7}$ The apparatus used for recording the paw edema was the mercury plethysmograph. ${ }^{8}$

Acute inflammation was induced by sub-plantar injection of $0.1 \mathrm{ml}$ of freshly prepared $1 \%$ suspension of carrageenan in normal saline in the right hind paw of the rats and paw volume are measured in plethysmometrically at zero hours and 3hours after carrageenan injection. Aspirin in $2.5 \mathrm{mg} / \mathrm{kg}$ body weight was administered orally 1 hour before carrageenan injection. Nifedipine dissolved in normal distilled water $5 \mathrm{mg} / \mathrm{kg}$ body weight was administered orally 1 hour before carrageenan injection. Amlodipine dissolved in normal distilled water $5 \mathrm{mg} / \mathrm{kg}$ body weight was administered orally 1 hour before carrageenan injection. Diltiazem dissolved in normal 
distilled water $4 \mathrm{mg} / \mathrm{kg}$ body weight was administered orally 1 hour before carrageenan injection. Mean increase in paw volume percentage inhibition of inflammatory swelling were calculated for each group of drugs at 0 and 3hours plethysmometrically. The group-I served as untreated control while group-II and group-III were designated as drug treated groups. The untreated group received normal saline $2 \mathrm{ml}$ orally. A convenient anatomical land mark was noted at the ankle to determine the dipping of the paw to the same level every time. One hour after the oral administration of normal saline in the control group and drugs in the test groups, a sub plantar injection of $0.1 \mathrm{ml}$ of freshly prepared $1 \%$ suspension of carrageenan in normal saline was made into the right hind paw of each rat of the respective groups.

\section{Method 1(B): Histamine induced hind paw edema}

The method used here in comprises the study of the acute inflammatory reaction induced by the histamine injected into the sub-planar surface of the right hind paw of rat according to the method of Winter et al. ${ }^{7}$ The apparatus used for recording the paw edema was the mercury plethysmograph (Maurya R et al,). ${ }^{8} 0.1 \mathrm{ml}$ of $0.1 \%$ solution of histamine acid phosphate was injected in the right hind paw, and the paw volume was measured plethysmometrically before and 1 hour after the injection. Drugs were administered as mentioned above and the rest procedure was as above.

\section{Method 2: Sub Acute Model of Inflammation}

Sub-acute inflammation was produced by granuloma pouch method by implanting cotton pellets. This method is widely used to study the exudative and proliferative phases of inflammation. The rats were subjected to halothane anaesthesia and small linear incision of about $1 \mathrm{~cm}$ was given in nape of the neck of the animal. Sterile cotton pellets $(5 \mathrm{mg})$ each impregnated with $0.4 \mathrm{ml}$ of $5 \%$ aqueous solution of Ampicillin were implanted in the inter-scapular area with aseptic precautions. The animals were maintained in clean cages food and water was allowed throughout the period of experimentation. On the $6^{\text {th }}$ day, the rats were again anaesthetized with halothane and pellets were dissected out dried in the oven at $60^{\circ} \mathrm{C}$ and dry weight of cotton pellet is determined. The weight of granulomatous tissue formed was calculated by noting the difference in the dry weight of the cotton pellet recorded before and after the implantation.

\section{Method 3: Chronic inflammation}

The method used here in comprises the study of the chronic inflammatory reaction induced by the $0.1 \mathrm{ml}$ of $2 \%$ formaldehyde injected into the sub-plantar surface of the right hind paw of rats on day 1 and day 3 . The apparatus used for recording the paw edema is the mercury plethysmograph (Maurya $\mathrm{R}$ et al). ${ }^{8}$ Drugs were administered as mentioned above and rest procedure was as above.

\section{RESULTS}

The anti-inflammatory response of drug aspirin was found to be significantly highest with percent inhibition of $72.4 \%$ the mean increase in paw volume was only $1.33 \mathrm{ml}$ with $\mathrm{t}$ value of 6.7 ( $p<0.001)$. Nifedipine anti-inflammatory response is less than Aspirin but more than diltiazem with percent inhibition of $65.60 \%$. It was observed that when amlodipine was used as an anti-inflammatory agent, the anti-inflammatory response of drug amlodipine was not significantly more than that of control percent inhibition ( $p$ $>0.05$ ) (Table 1). The anti-inflammatory response of drug aspirin was found to be significantly highest with percent inhibition of $75.80 \%$ the mean increase in paw volume was only $1.33 \mathrm{ml}$ with $\mathrm{t}$ value of 6.93 ( $\mathrm{p}<0.001)$. Antiinflammatory response of drug nifedipine is less than aspirin more than diltiazem. Amlodipine was not significantly more than that of control percent inhibition ( $p$ $>0.05$ ). Anti-inflammatory response of drug diltiazem is less than nifedipine more than amlodipine (Table 2).

Table 1: Effect of calcium channel blockers and aspirin on rat hind paw inflammation induced by carrageenan (acute inflammatory model).

\begin{tabular}{|c|c|c|c|c|c|c|}
\hline Groups & $\begin{array}{l}\text { Paw volume in } \mathrm{ml} \\
\text { Difference } \mathbf{R} \text { - } \mathbf{L} \text { a }\end{array}$ & 6 rats & $\begin{array}{l}\text { Mean paw } \\
\text { volume }\end{array}$ & $\%$ inhibition & T value & P value \\
\hline \multirow{2}{*}{ Control (normal saline) } & 5 & 4 & \multirow{2}{*}{$4.83 \pm 0.47$} & \multirow{2}{*}{-} & \multirow{2}{*}{-} & \multirow{2}{*}{-} \\
\hline & 3 & 5 & & & & \\
\hline \multirow{2}{*}{ Aspirin } & 2 & 1 & \multirow{2}{*}{$1.33 \pm 0.21$} & \multirow{2}{*}{$72.40 \%$} & \multirow{2}{*}{6.708} & \multirow{2}{*}{$<0.001$} \\
\hline & 2 & 1 & & & & \\
\hline \multirow{2}{*}{ Nifedipine } & 3 & 1 & \multirow{2}{*}{$1.67 \pm 0.33$} & \multirow{2}{*}{$65.60 \%$} & \multirow{2}{*}{5.44} & \multirow{2}{*}{$<0.001$} \\
\hline & 2 & 2 & & & & \\
\hline \multirow{2}{*}{ Diltiazem } & 2 & 1 & \multirow{2}{*}{$2.33 \pm 0.42$} & \multirow{2}{*}{$51.70 \%$} & \multirow{2}{*}{3.92} & \multirow{2}{*}{0.003} \\
\hline & 2 & 4 & & & & \\
\hline \multirow[b]{2}{*}{ Amlodipine } & 4 & 5 & \multirow[t]{2}{*}{$4.5 \pm 0.22$} & \multirow[b]{2}{*}{$6.80 \%$} & \multirow[b]{2}{*}{0.632} & \multirow[b]{2}{*}{0.541} \\
\hline & 5 & 5 & & & & \\
\hline
\end{tabular}


Table 2: Effect of calcium channel blockers and aspirin on rat hind paw inflammation induced by histamine (acute inflammatory model).

\begin{tabular}{|c|c|c|c|c|c|c|}
\hline Groups & $\begin{array}{l}\text { Paw volume in } \mathbf{~} \\
\text { Difference } \mathbf{R} \text { - } \mathbf{L} \text { a }\end{array}$ & 6 rats & $\begin{array}{l}\text { Mean paw } \\
\text { volume }\end{array}$ & $\%$ inhibition & T value & P value \\
\hline \multirow{2}{*}{ Control (normal saline) } & $\begin{array}{ll}7 & 6\end{array}$ & 3 & \multirow{2}{*}{$5.5 \pm 0.56$} & \multirow[b]{2}{*}{-} & \multirow[b]{2}{*}{-} & \multirow[b]{2}{*}{-} \\
\hline & 6 & 6 & & & & \\
\hline \multirow{2}{*}{ Aspirin } & 2 & 1 & \multirow{2}{*}{$1.33 \pm 0.21$} & \multirow{2}{*}{$75.80 \%$} & \multirow{2}{*}{6.93} & \multirow{2}{*}{$<0.001$} \\
\hline & 2 & 1 & & & & \\
\hline \multirow{2}{*}{ Nifedipine } & 2 & 2 & \multirow{2}{*}{$1.83 \pm 0.30$} & \multirow{2}{*}{$66.70 \%$} & \multirow{2}{*}{5.771} & \multirow{2}{*}{0.001} \\
\hline & 1 & 1 & & & & \\
\hline \multirow{2}{*}{ Diltiazem } & 4 & 2 & \multirow{2}{*}{$3 \pm 0.36$} & \multirow{2}{*}{$45.40 \%$} & \multirow{2}{*}{3.72} & \multirow{2}{*}{0.004} \\
\hline & 4 & 3 & & & & \\
\hline \multirow{2}{*}{ Amlodipine } & 5 & 5 & \multirow{2}{*}{$5.16 \pm 0.16$} & \multirow{2}{*}{$6.18 \%$} & \multirow{2}{*}{0.568} & \multirow{2}{*}{0.583} \\
\hline & 5 & 5 & & & & \\
\hline
\end{tabular}

Table 3: Effect of calcium channel blockers and aspirin on rat hind paw inflammation induced by formaldehyde (chronic inflammatory model).

\begin{tabular}{|c|c|c|c|c|c|c|c|c|c|c|}
\hline & \multicolumn{2}{|l|}{ Day 1} & \multicolumn{2}{|l|}{ Day 2} & \multicolumn{2}{|l|}{ Day 3} & \multicolumn{2}{|l|}{ Day 4} & \multicolumn{2}{|l|}{ Day 5} \\
\hline & $\begin{array}{l}\text { Mean } \\
\pm \text { SE }\end{array}$ & $\begin{array}{l}\% \\
\text { inhibition }\end{array}$ & $\begin{array}{l}\text { Mean } \\
\pm \text { SE }\end{array}$ & $\begin{array}{l}\% \\
\text { inhibition }\end{array}$ & $\begin{array}{l}\text { Mean } \\
\pm \text { SE }\end{array}$ & $\begin{array}{l}\% \\
\text { inhibition }\end{array}$ & $\begin{array}{l}\text { Mean } \\
\pm \text { SE }\end{array}$ & $\begin{array}{l}\% \\
\text { inhibition }\end{array}$ & $\begin{array}{l}\text { Mean } \\
\pm \text { SE }\end{array}$ & $\begin{array}{l}\% \\
\text { inhibition }\end{array}$ \\
\hline Aspirin & $\begin{array}{l}2.16 \\
\pm 0.41\end{array}$ & 50.11 & $\begin{array}{l}1.2 \\
\pm 0.17\end{array}$ & 80 & $\begin{array}{l}1.33 \\
\pm 0.21\end{array}$ & 84.03 & $\begin{array}{l}1.00 \\
\pm 0.0\end{array}$ & 88.9 & $\begin{array}{l}0.33 \\
\pm 0.21\end{array}$ & 96.2 \\
\hline Nifedipine & $\begin{array}{l}3 \\
\pm 0.89\end{array}$ & 30.72 & $\begin{array}{l}1.8 \\
\pm 0.31 \\
\end{array}$ & 68.44 & $\begin{array}{l}2 \\
\pm 0.37\end{array}$ & 76 & $\begin{array}{l}1.5 \\
\pm 0.34\end{array}$ & 83.3 & $\begin{array}{l}0.83 \\
\pm 0.17\end{array}$ & 90.7 \\
\hline Diltiazem & $\begin{array}{l}3.67 \\
\pm 0.82 \\
\end{array}$ & 15.24 & $\begin{array}{l}3.5 \\
\pm 0.34 \\
\end{array}$ & 39.67 & $\begin{array}{l}3.83 \\
\pm 0.40 \\
\end{array}$ & 54 & $\begin{array}{l}3 \\
\pm 0.37 \\
\end{array}$ & 66.7 & $\begin{array}{l}2.17 \\
\pm 0.48 \\
\end{array}$ & 75.9 \\
\hline Amlodipine & $\begin{array}{l}4.17 \\
\pm 0.75\end{array}$ & 3.7 & $\begin{array}{l}5.3 \\
\pm 0.33 \\
\end{array}$ & 8.6 & $\begin{array}{l}7.83 \\
\pm 0.48\end{array}$ & 6 & $\begin{array}{l}8.5 \\
\pm 0.67\end{array}$ & 5.5 & $\begin{array}{l}8.67 \\
\pm 0.56\end{array}$ & 3.7 \\
\hline Control & $\begin{array}{l}4.33 \\
\pm 0.52\end{array}$ & - & $\begin{array}{l}5.8 \\
\pm 0.31\end{array}$ & - & $\begin{array}{l}8.33 \\
\pm 0.42\end{array}$ & - & $\begin{array}{l}9 \\
\pm 0.58\end{array}$ & - & $\begin{array}{l}9 \\
\pm 0.56\end{array}$ & - \\
\hline
\end{tabular}

Table 4: Cotton wool pellet granuloma: (sub-acute inflammation).

\begin{tabular}{|c|c|c|c|c|c|c|c|}
\hline Groups & \multicolumn{3}{|c|}{ Dry Wt. granuloma (mg) } & $\begin{array}{l}\text { Mean dry } \\
\text { granuloma wt (mg) }\end{array}$ & $\begin{array}{l}\% \\
\text { inhibition }\end{array}$ & T value & $P$ value \\
\hline \multirow{2}{*}{ Control (normal saline) } & 51 & 52 & 51 & \multirow{2}{*}{$51.5 \pm 0.34$} & \multirow{2}{*}{ 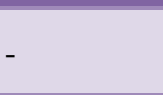 } & \multirow[b]{2}{*}{-} & \multirow{2}{*}{-} \\
\hline & 51 & 53 & 51 & & & & \\
\hline \multirow{2}{*}{ Aspirin } & 21 & 20 & 23 & \multirow{2}{*}{$21.3 \pm 0.42$} & \multirow{2}{*}{58.64} & \multirow{2}{*}{55.6} & \multirow{2}{*}{$<0.001$} \\
\hline & 21 & 21 & 22 & & & & \\
\hline \multirow{2}{*}{ Nifedipine } & 32 & 32 & 34 & \multirow{2}{*}{$32 \pm 0.52$} & \multirow{2}{*}{37.86} & \multirow{2}{*}{31.5} & \multirow{2}{*}{$<0.001$} \\
\hline & 30 & 32 & 32 & & & & \\
\hline \multirow{2}{*}{ Diltiazem } & 37 & 35 & 38 & \multirow{2}{*}{$36.3 \pm 0.61$} & \multirow{2}{*}{29.51} & \multirow{2}{*}{21.57} & \multirow{2}{*}{$<0.001$} \\
\hline & 38 & 35 & 38 & & & & \\
\hline \multirow{2}{*}{ Amlodipine } & 47 & 46 & 46 & \multirow{2}{*}{$47 \pm 0.45$} & \multirow{2}{*}{8.73} & \multirow{2}{*}{7.9} & \multirow{2}{*}{0.051} \\
\hline & 49 & 47 & 47 & & & & \\
\hline
\end{tabular}

It was observed that with the use of anti-inflammatory drug Aspirin the day 5 percent inhibition was highest at $96.2 \%$ followed by nifedipine at $90.7 \%$ diltiazem $75.9 \%$ and Amlodipine at $3.7 \%$. The $5^{\text {th }}$ day percent increase in mean of the right hind paw volume was found to be least for aspirin followed by nifedipine, diltiazem and amlodipine (Table 3). In the present study it was observed that the mean dry granuloma weight was least for aspirin and percent anti-inflammatory activity was significantly higher with $t$ value of $55.6(\mathrm{p}<0.001)$.

For nifedipine and mean dry granuloma weight was less than aspirin and more than diltiazem with $\mathrm{t}$ value of 31.5 (p $<0.001)$. For diltiazem and mean dry granuloma weight was less than Nifedipine and more than Amlodipine with $\mathrm{t}$ value of 21.57 ( $p<0.001)$. The mean dry weight granuloma 
$8 \%$ anti-inflammatory activity of amlodipine was not significantly higher than control t value 7.9 ( $\mathrm{p}>0.05)$ (Table 4).

\section{DISCUSSION}

Results of the present study indicate that calcium channel blockers nifedipine and diltiazem possess $(\mathrm{P}<0.001)$ Antiinflammatory property in acute, sub-acute and chronic models of inflammation which were comparable to that of aspirin ( $\mathrm{P}<0.001)$. Among the 3 calcium channel blockers only amlodipine did not show anti-inflammatory effect when compared to aspirin.

The present study is done in carrageenan and histamine induced hind paw edema method for acute model of Inflammation, cotton wool pellet granuloma used for subacute inflammation formaldehyde induced arthritis for chronic model of inflammation.

The possible mechanisms involved in the antiinflammatory activity L-type of CCBs may be through Lake BG et al, Rodler S et al, Southan GJ et al, Craven PA et al. ${ }^{9-12}$ A reduction of the $\mathrm{Ca}^{2+}$ concentration in blood, causing a decrease in the vessel resistance, and consequent reduction of hydrostatic pressure in the capillaries, inhibition of the release of pro-inflammatory mediators by inhibiting the voltage dependent calcium entry, reduction of $\mathrm{Ca}^{2+}$ leading to inhibition of the activity of PLA2 and/ or PLC, the enzymes responsible for the synthesis of eicosanoids and leukotrienes. Stabilization of the cell membrane integrity (by inhibiting $\mathrm{Ca}^{2+}$ influx), thus preventing tissue injury and inflammation.

Aditya GN et al, in their study concluded that nifedipine produce significant and dose dependant anti-inflammatory effect in rat hind paw edema and was found to be more potent as compared to Aspirin. ${ }^{13}$ Authors also found that nifedipine was the most potent among all test drugs but its efficacy was lower as compared to aspirin which is in contrast to the study by Aditya GN et al. ${ }^{13}$

Khaksari M et al, noted that the reduction in the edema was dose dependent. ${ }^{14}$ They also observed that verapamil at low doses was effective and not in higher doses. Verapamil and nifedipine effect were prevented by adrenalectomy. The anti-inflammatory effect of nifedipine was $66 \%$ at low doses before the treatment was given with $\alpha$-corticotropin releasing factor. $\alpha$-corticotropin releasing factor is an antagonist to corticotropin releasing hormone $(\mathrm{CRH})$ receptor. It is as good as adrenalectomy. This factor can prevent only the low dose nifedipine effect.

Gitanjali $\mathrm{K}$ et al, studied anti-inflammatory activities of calcium channel blockers. ${ }^{15}$ They observed that the formaldehyde, histamine and carrageenan induced acute inflammation in the rats. But this was effectively decreased by all calcium channel blockers except nimodipine. The result was statistically significant for all calcium channel blockers except nimodipine $(\mathrm{p}<0.05)$. These findings are similar to the findings of the present study. Similar to the present study, the authors also used cotton pellet implantation for sub-acute inflammation and then tested the effectiveness of calcium channel blockers. They found similar results as mentioned above.

Since NSAIDs have many adverse effects including ulcerogenic, renal toxicity, hypertension the search for a better and less toxic drug is going on calcium channel blocker have shown comparable anti-inflammatory property so they can be used for this purpose or they can be used as adjuvants along with NSAIDs by reducing their dosage. Anyway, further studies and clinical trials are required to confirm their effectiveness.

\section{CONCLUSION}

The anti-inflammatory property of calcium blockers nifedipine, amlodipine, diltiazem was observed by inducing acute, sub-acute and chronic inflammation in Albino rats and was compared with that of Aspirin. Among the 3 calcium channel blockers, nifedipine showed the maximum anti-inflammatory response in acute, sub-acute and chronic inflammation. The anti-inflammatory response of diltiazem was comparable to aspirin but less than that of nifedipine more than Amlodipine. Amlodipine showed no anti-inflammatory response in acute sub-acute and chronic inflammatory models.

\section{Funding: No funding sources}

Conflict of interest: None declared

Ethical approval: The study was approved by the Institutional Ethics Committee

\section{REFERENCES}

1. Paterson JR, Baxter G, Dreyer JS, Halket JM, Flynn $\mathrm{R}$, Lawrence JR. Salicylic acid sans aspirin in animals and man: persistence in fasting and biosynthesis from benzoic acid. J Agricultural Food Chem. 2008 Nov 20;56(24):11648-52.

2. Lewis HD, Davis JW, Archibald DG, Steinke WE, Smitherman TC, Doherty JE, et al. Protective effects of aspirin against acute myocardial infarction and death in men with unstable angina. $\mathrm{N}$ Engl J Med. 1983 Aug 18;309(7):396-403.

3. Julian DG, Chamberlain DA, Pocock SJ. A comparison of aspirin and anticoagulation following thrombolysis for myocardial infarction (the AFTER study): a multicentre unblinded randomised clinical trial. BMJ. 1996 Dec 7;313(7070):1429-31.

4. Krumholz HM, Radford MJ, Ellerbeck EF, Hennen J, Meehan TP, Petrillo M, et al. Aspirin in the treatment of acute myocardial infarction in elderly Medicare beneficiaries: patterns of use and outcomes. Circulation. 1995 Nov 15;92(10):2841-7.

5. Algra AM, Rothwell PM. Effects of regular aspirin on long-term cancer incidence and metastasis: a systematic comparison of evidence from observational 
studies versus randomised trials. Lancet Oncol. 2012 May 1;13(5):518-27.

6. Rothwell PM, Price JF, Fowkes FG, Zanchetti A, Roncaglioni MC, Tognoni G, et al. Short-term effects of daily aspirin on cancer incidence, mortality, and non-vascular death: analysis of the time course of risks and benefits in 51 randomised controlled trials. Lancet. 2012 Apr 28;379(9826):1602-12.

7. Winter CA, Risley EA, Nuss GW. Carrageenininduced edema in hind paw of the rat as an assay for antiinflammatory drugs. Proceed Soc Exp Biol Med. 1962 Dec;111(3):544-7.

8. Maurya R, Yadav DK, Singh G, Bhargavan B, Murthy PN, Sahai M, et al. Osteogenic activity of constituents from Butea monosperma. Bioorganic Med Chem Lett. 2009 Feb 1;19(3):610-3.

9. Lake-Bakaar G, Lyubsky S. Dose-dependent effect of continuous subcutaneous verapamil infusion on experimental acute pancreatitis in mice. Digestive Dis Sci. 1995 Nov 1;40(11):2349-55.

10. Rödler S, Roth M, Nauck M, Tamm M, Block LH. $\mathrm{Ca} 2+$-channel blockers modulate the expression of interleukin-6 and interleukin-8 genes in human vascular smooth muscle cells. J Mol Cellular Cardiol. 1995 Oct 1;27(10):2295-302.

11. Southan GJ, Szabó C. Selective pharmacological inhibition of distinct nitric oxide synthase isoforms. Biochem pharmacol. 1996 Feb 23;51(4):383-94.
12. Craven PA, DeRubertis FR. Ca2+. Calmodulindependent release of arachidonic acid for renal medullary prostaglandin synthesis. Evidence for involvement of phospholipases A2 and C. J Biol Chem. 1983 Apr 25;258(8):4814-23.

13. Aditya GN, Chattopadhyay RN, Mandal S, Roy RK, Lahiri HL, Maitra SK. Preliminary study on antiinflammatory effect of calcium channel blockers in albino rats. Indian J Pharmacol. 1997 Mar $1 ; 29(2): 132$.

14. Khaksari M, Mahani SE, Mahmoodi M. Calcium channel blockers reduce inflammatory edema in the rat: Involvement of the hypothalamus-pituitaryadrenal axis. Indian J Pharmacol. 2004 Nov $1 ; 36(6): 351-4$.

15. Gitanjali K, Gupta B, Vijay T. Anti-inflammatory activity of calcium channel blockers. Int J Life Sci Pharma Res. 2012;2(2):1-6.

Cite this article as: Jabeen A. Comparative study of anti-inflammatory property of calcium channel blocker and aspirin in albino rats. Int $\mathrm{J}$ Basic Clin Pharmacol 2019;8:21-6. 